\title{
SALMONELLA CHOLERAESUIS SEPTICAEMIA COMPLICATING RHEUMATIC HEART DISEASE
}

\author{
A. R. HoRleR, M.D., M.R.C.P. \\ Senior Medical Registrar, Royal Victoria Infirmary, Newcastle upon Tyne \\ G. IsMAY, M.D., M.R.C.P. \\ Physician, Durham and South-West Durham Groups of Hospitals \\ Formerly Senior Medical Registrar, Royal Victoria Infirmary, Newcastle upon Tyne
}

The first report of a case of human infection with Salmonella choleraesuis was made by Longcope in I902. ${ }^{6}$ The clinical manifestations of infection with this organism have been described by Harvey, ${ }^{4}$ who reviewed the literature up to that date and added $2 \mathrm{I}$ cases of his own treated at the Johns Hopkins Hospital, and have been further elaborated by Saphra and Wassermann, ${ }^{12}$ who identified the organism from 329 patients investigated at the New York Salmonella Centre. A septicaemic illness resembling typhoid is the commonest presentation; other features include respiratory infection, urinary tract infection and pyaemic localizations, such as osteomyelitis, pyogenic arthritis and psoas abscess. For a salmonella infection, diarrhoea is relatively uncommon; Saphra and Wassermann were able to culture the organism from the faeces in only 23 of their 329 cases. Occasionally it may complicate an infection with another organism, e.g. meningococcal meningitis ${ }^{8}{ }^{9}$ and scarlet fever. ${ }^{\text {? }}$

A rare site of infection with Salmonella choleraesuis is the endocardium. Ten of the 329 patients reported by Saphra and Wassermann had bacterial endocarditis, and Rich and St. Mary, ${ }^{11}$ in reporting a case of their own, could find only 13 other examples in the literature. Indeed, the total number of cases of endocarditis due to all salmonellae published between the years 1929 and 1956 was only 24 . Infection with Salmonella choleraesuis can occur on a heart valve previously damaged by acute rheumatism ${ }^{3,11}$ as a complication of syphilitic heart disease ${ }^{3}$ or on apparently healthy heart valves. ${ }^{10}$ It can also affect the coronary arteries, giving rise to arteritis and thrombosis. ${ }^{1}$

The incidence of systemic infection with $\mathrm{Sal}$ monella choleraesuis in Great Britain is low. Laylee in $1957^{5}$ could find only 12 previously reported cases in this country. A man with fatal septicaemia due to this organism has recently been treated in the Royal Victoria Infirmary, Newcastle upon Tyne. He also had rheumatic heart disease.

\section{Case Report}

A 54-year-old man, an insurance agent, was admitted under the care of Dr. C. N. Armstrong on February 16, 1952. When aged ro years he had had rheumatic fever and for ro years before admission he had noticed dyspnoea on exertion. Six years before admission he had had a small haemoptysis. He gave a four months' history of lethargy, aching limbs, attacks of sweating ane shivering, loss of weight, and an increase of breath lessness. In addition, he complained of a cramping pain in the legs on exertion which passed off with rest. Vomiting occasionally occurred in the early morning and, although his bowels were normal at the time of admission, he admitted having had a short bout of diarrhoea five months before.

His general condition on examination was fairly good. He ran an intermittent pyrexia of up to 101.2 ${ }^{\circ}$ while in hospital. There was no cardiac irregularity and the apex rate was 72 per minute. A rough systolic murmur was heard, loudest at the aortic area, and a mid-diastolic murmur at the apex. His blood pressure was $120 / 80$. He was considered to have rheumatic aortic and mitral stenosis. There was no enlargement of the spleen, although a few enlarged lymph nodes were palpable in the left axilla.

Radiological examination of the chest and heart demonstrated left ventricular enlargement and some old calcified tuberculous foci. The electrocardiogram showed evidence of left ventricular hypertrophy and strain. Haematological investigation revealed a hypochromic anaemia and marked lymphocytosis: haemoglobin 9.9 g. \%, red blood cells 4.78 million per cu. mm., white blood cells 26,800 per cu. mm., lymphocytes $73 \%$, neutrophils $24 \%$, monocytes $2 \%$ and eosinophils $1 \%$. Many degenerate cells were seen and the film was 
reported as being compatible with a diagnosis of chronic lymphatic leukaemia. Microscopic examination of the urine was negative and there was no albuminuria. A blood culture taken at this time was reported as growing ' coliform organisms' sensitive to streptomycin and chloromycetin. $\mathrm{He}$ was discharged home on iron by mouth, with a presumptive diagnosis of rheumatic heart disease and chronic lymphatic leukaemia.

He felt better after leaving hospital, although still weak and rather shaky on his legs. After a month he began to complain of a recurrence of night sweats and of aching in his back and legs. After a rigor, during which his temperature rose to $103^{\circ} \mathrm{F}$., he was readmitted to hospital on April 2, 1952. The cardiac signs were unaltered and the lymph nodes in the left axilla were still palpably enlarged. There was early finger clubbing. On the third day of his admission he had a severe rigor accompanied by profuse sweating, delirium and a rise in temperature to $103.4^{\circ} \mathrm{F}$. $\mathrm{He}$ had further similar attacks and developed a generalized purpuric rash. A blood culture taken during a febrile episode grew organisms of the salmonella group, which were later identified by Dr. G. Hutchinson as Salmonella choleraesuis. His serum was found to agglutinate $S$. choleraesuis to a dilution of $1-2,500$. Repeated blood cultures were positive, although the organism could not be grown from urine or faeces. He was still moderately anaemic: haemoglobin II g. \%, red blood cells 4.53 million per cu. mm., white blood cells I I 600 per cu. mm., lymphocytes $47 \%$ neutrophils $38 \%$, band forms $7 \%$, monocytes $5 \%$, eosinophils $3 \%$. The E.S.R. (Westergren) was $56 \mathrm{~mm}$. in one hour. His sternal marrow showed normoblastic erythropoiesis, and $37 \%$ of the total cell count was made up of lymphocytes.

He was regarded as suffering from Salmonella choleraesuis septicaemia with infective endocarditis and was treated with intramuscular streptomycin, I g. twice daily for one week. This was discontinued and chloramphenicol in large dosage by mouth was begun. For the first two days he was given $500 \mathrm{mg}$. six-hourly; for the next five days this was increased to $1,500 \mathrm{mg}$. six-hourly, and thereafter he received I g. sixhourly over the succeeding five weeks. The blood culture became negative, although the agglutinations remained positive to a high titre-up to $\mathrm{I} / 5,000^{\prime}$ ' $\mathrm{H}$ ' and $\mathrm{I} / 25^{\circ}$ ' $\mathrm{O}$ '. He became afebrile soon after starting the chloramphenicol and at the end of the course his E.S.R. (Westergren) was $10 \mathrm{~mm}$. in one hour.

He was discharged from hospital on June 12, 1952, and when reviewed a month later he complained of fatigue and breathlessness on exertion. The lymphadenopathy had disappeared, he was afebrile and the E.S.R. (Westergren) was $6 \mathrm{~mm}$. in one hour. Blood culture was negative, although agglutination reactions remained strongly positive against Salmonella choleraesuis ( $\mathrm{H}$ ' $\mathrm{I} / 2,500$ and ' $\mathrm{O}$ ' $\mathrm{I} / 25^{\circ}$ ). The blood picture had reverted almost to normal: haemoglobin 15.4 g. \%, white blood cells 12,300 per cu. mm., neutrophils $52 \%$, lymphocytes $41 \%$, monocytes $6 \%$, eosinophils $1 \%$. On subsequent visits up to the end of $195^{2}$ his white cell count remained in the neighbourhood of 12,000 per cu. mm., with a moderate increase of mature lymphocytes. Blood cultures were repeatedly negative. It was considered that the salmonella infection had been eradicated by the antibiotic therapy.

$\mathrm{He}$ attended for review in September 1956, when he complained of breathlessness and anginal pain on exertion. There was no evidence of congestive heart failure and his heart sounds were unchanged. There was no discernible enlargement of the liver or spleen and no lymphadenopathy. Screening of the heart (G.I.) confirmed enlargement of the left atrium and of the left ventricle.

On December 5, 1956, he was readmitted to hospital complaining of a cough of six weeks' duration accompanied by a tight pain across the front of the chest. Although afebrile, he appeared pale and ill and enlarged lymph nodes were palpable in the axillae and groins. The liver and spleen were both palpably enlarged two fingers' breadth below the costal margin. The cardiac signs were unchanged. Examination of the blood revealed a return of the anaemia and absolute lymphocytosis: haemoglobin $9.6 \mathrm{~g}$. \%, red blood cells 4.30 million per cu. mm., white blood cells 30,000 per cu. mm., neutrophils $8 \%$, lymphocytes $69 \%$, smear cells $20 \%$, monocytes $3 \%$. Repeated blood cultures were negative, although agglutination reactions remained strongly positive against Salmonella choleraesuis (' $\mathrm{O}$ ' $\mathrm{I} / \mathrm{I} 25$, ' $\mathrm{H}$ ' $\mathrm{I} / 5, \infty 00$ ). No pathogenic organisms were cultured from an aspirate of an inguinal lymph node. The chest radiograph revealed an increase in the size of the heart shadow, some fluid in the right pleural cavity and pulmonary striations indicative of congestion. He was discharged from hospital on Christmas Eve, 1956.

He remained fairly well until the beginning of March I957, when he became increasingly short of breath and developed swelling of the ankles. In addition, his temperature was raised and he had intermittent attacks of flushing and sweating, reminiscent of his initial illness. He was treated at home with digitalis and diuretics, but eventually was admitted to hospital for the last time on April 1, 1957. On this occasion his temperature was $99^{\circ} \mathrm{F}$. and his pulse rate 126 per minute. There was evident congestive failure with marked 
dyspnoea even at rest, and extensive oedema of his legs and sacrum. The liver and spleen were enlarged and there was enlargement of the axillary and inguinal lymph nodes. There were signs of a right-sided pleural effusion. Blood cultures were again negative and agglutinations against $\mathrm{Sal}$ monella choleraesuis were strongly positive. The blood count was as follows: haemoglobin IC.2 g. $\%$, white blood cells IOI,000 per cu. mm., $90 \%$ of the white cells consisting of small mature lymphocytes. Later the white cell count rose to 136,000 per cu. mm., of which $88 \%$ were small lymphocytes. In spite of digitalis, mercurial diuretics and chloramphenicol, he died on April I4, 1957.

At autopsy (performed by Dr. W. J. Still) the heart was found to weigh $510 \mathrm{~g}$. There was thickening of the posterior cusp of the mitral valve with some fibrosis of the chordae tendineae, but no real stenosis present. The aortic valve showed a severe degree of stenosis with calcification, but no evidence of infective endocarditis. There was some thickening of the wall of the left ventricle (23 $\mathrm{mm}$. being the maximum thickness), a diffuse fibrosis of the trabecular layer of muscle, and slight diffuse thickening of the endocardium. A moderate degree of atheroma of the coronary arteries was found. There was much fluid in both pleural cavities, congestion and oedema of the lungs, and some bronchiectasis in the right middle lobe.

There was enlargement and congestion of the liver. The spleen was found to weigh $400 \mathrm{~g}$. and to be soft in consistency. Many groups of lymph nodes were moderately enlarged. An enlarged mass of nodes was found at the lower end of the aorta; suppuration had occurred and creamy yellow pus had tracked into the sheath of the right psoas muscle. At that site there was a small aneurysm of the abdominal aorta containing layers of organized thrombus. The bone marrow was of normal appearance.

Histological examination of the aortic valve revealed an old rheumatic process, with no evidence of infective endocarditis. The architecture of the spleen and lymph nodes was roughly preserved, although there was infiltration with an abnormal number of mononuclear cells. There was no indication of a leukaemic process; rather did the appearances suggest a chronic infection.

Salmonella choleraesuis was cultured from the abscess at the lower end of the aorta. No pathogenic organisms were grown from the aortic valve, from the spleen or from a lymph node.

\section{Discussion}

There can be little doubt that this patient harboured Salmonellae choleraesuis throughout the whole five years of his illness, although the original florid septicaemia was suppressed by vigorous antibiotic therapy early in the course of the disease. It is uncertain whether at any time he had a bacterial endocarditis affecting his aortic valve, the site of a previous rheumatic valvulitis. No evidence of such an infection was found at postmortem examination. Nevertheless, the initial presentation, with a pyrexial illness, anaemia, finger clubbing, generalized purpura, a demonstrable valvular lesion, and a positive blood culture, would seem to fulfil many of the criteria for a diagnosis of bacterial endocarditis. It is likely that the prolonged course of chloramphenicol in high dosage was sufficient to eradicate the infection of the heart valves.

A more difficult problem during life was whether, in fact, the salmonella infection was complicating an existing chronic lymphatic leukaemia, or whether it was producing a marked lymphocytosis in the peripheral blood. Salmonella infections are known to occur as complications of primary haematological disorders, such as idiopathic thrombocytopenic purpura ${ }^{5}$ and acute lymphoblastic leukaemia. ${ }^{13}$ Chronic lymphatic leukaemia was originally diagnosed in our patient on his first hospital admission, when his leucocyte count was 26,800 per cu. $\mathrm{mm}$., $73 \%$ of which were mature lymphocytes. However, at that time his spleen was impalpable and only one group of lymph nodeso was enlarged. Later blood counts were less characteristic; during his second admission the total white cell count was I I,600 per cu. mm., of which only $47 \%$. were lymphocytes. Moreover, after the course of chloramphenicol the lymphadenopathy disappeared and the blood picture, including the haemoglobin level, reverted virtually to normal. Thereafter the white cell count remained at around 12,000 per cu. mm., with a moderate lymphocytosis until a relapse of his septicaemic illness late in 1956 . It then rose until terminally it had reached 136,000 per cu. $\mathrm{mm}$. This was accompanied by a reappearance of the lymphadenopathy and enlargement of the liver and spleen. Finally, the autopsy findings in spleen and lymph nodes were those of a chronic inflammatory process rather than leukaemic infiltration.

The blood picture in Salmonella choleraesuis septicaemia would seem to be very variable. Harvey ${ }^{4}$ considered that in an uncomplicated bacteraemia presenting like typhoid the leucocyte count tended to be low, and in 19 such patients the range was 1,700 to 14,600 with an average of 6,800 per cu. mm. When the infection localized and abscess formation resulted the leucocyte count was then higher and might rise to 80,000 per cu. $\mathrm{mm}$. This sequence was also reported by Ravitch and Washington ${ }^{9}$ and Neter. ${ }^{8}$ Although 
the white cell count in our patient rose terminally to high levels (136,000 per cu. mm., of which $88 \%$ were small lymphocytes), it is considered that the blood picture and also the lymphadenopathy and splenomegaly could be ascribed wholly to the septicaemic process. The second of the two patients reported by Dell'Acqua ${ }^{2}$ presented a similar picture, with a leucocyte count rising to I 8,500 per cu. mm., $95 \%$ being of the lymphocytic series and mostly immature. In due course a pancytopenia supervened.

Abscess formation and other focal manifestations, such as osteomyelitis, are frequent complications of Salmonella choleraesuis septicaemia and the psoas muscle is a known site of suppuration. ${ }^{12}$ In our patient a chronic abscess was found at autopsy situated near the bifurcation of the aorta. This had arisen from a suppurating mass of lymph nodes of the para-aortic group and had extended into the sheath of the right psoas muscle. The organisms were recoverable from the pus and it is thought likely that this was the locus of infection which resisted antibiotic treatment during his original illness and led to an exacerbation of the infection terminally.

\section{Summary}

The case report of a man with Salmonella choleraesuis septicaemia is presented. He had, in addition, rheumatic heart disease and, although evidence of bacterial endocarditis was lacking at autopsy, it is strongly suspected that such a complication was initially present. A lymphocytic blood picture originally led to a mistaken diagnosis of chronic lymphatic leukaemia.

A prolonged course of chloramphenicol produced a clinical remission lasting for over four years, but failed to eradicate the infection which persisted as a chronic abscess at the site of the lower para-aortic lymph nodes.

\section{Acknowledgments}

We wish to thank Dr. C. N. Armstrong for permission to publish this case report. We are also grateful to Dr. G. Hutchinson for bacteriological assistance, to Dr. W. J. Still, from whose autopsy report we freely quoted, and to Dr. I. Rannie for his helpful advice.

\section{REFERENCES}

I. BARNETT, R. N., and ZIMMERMAN, S. L. (1947), Amer. Heart $\mathcal{F}_{.3}, 34,441$.

. DELL'AC̈QU,

3. FORSTER, D. E. (1939), Amer. F. med. Sci., 197, 234.

4. HARVEY. A. M. (1937), Arch. intern. Med., 59, 118.

5. LAYLEE, A. M. (1957), Brit. med. $\mathcal{F}_{\text {., }}$ i, 1284.

6. LONGCOPE, W. T. (I002), Amer. F. med. Sci., 124, 200

7. NETER, E. R. (1942), Amer. ₹. Dis. Child., 64, 255.

8. NETER, E. R. (1943), $\mathcal{F}$. Pediat., $23,562$.

9. RAVITCH, M. M., and WASHINGTON, J. A. (1937), $f$ Amer. med. Ass., rog, 1122.

10. READ, C. T. (1939), Ұ. inf. Dis., 65, 263.

II. RICH, M., and ST. MARY, E. (1956), Ann. intern. Med., 44, 162.

12. SAPHRA, I., and WASSERMANN, M. (1954), Amer. f. med.

13. TEGELAERS, W. H. H., VEENEKLAAS, G. M. H., CARENBURG, A., and VINK, H. H. (1948), Ned. T. Geneesk., 92, 19 19.

\section{ENDOCRINE TUMOURS}

(Postgraduate Medical Journal, March 1960)

Price 6s. 6d. post free

ISLET-CELL TUMOURS AND PEPTIC ULCERATION

James B. Gibson, M.D., M.R.C.P.(Edin.), and Richard B. Welbourn, M.A., M.D.(Camb.), F.R.C.S.

ISLET-CELL TUMOUR OF THE PANCREAS, WITH HYPOGLYCAEMIA

Robert S. Monro, F.R.C.S.

PHAEOCHROMOCYTOMA

J. T. Wright, D.M., M.R.C.P.
VIRILIZING SYNDROMES

Ivor H. Mills, Ph.D., M.D., M.R.C.P.

BILATERAL POLYCYSTIC OVARIES

David Ferriman, D.M., M.R.C.P.

FEMINIZING TUMOURS OF THE TESTIS

P. Paton Philip, M.Chir., F.R.C.S.

CONN'S SYNDROME

T. M. Chalmers, M.D., M.R.C.P.

THE FELLOWSHIP OF POSTGRADUATE MEDICINE

60, Portland Place, London, W.1 